\title{
SMART KEY CHAIN LOCATION TRACKING ALARM ALERT
}

\author{
Muhammad Khozainul Asror Ridho \\ Fakultas Teknik, Program Studi Teknik Informatika \\ Universitas Muria Kudus \\ Email:201651022@std.umk.ac.id \\ Mukhamad Nurkamid \\ Fakultas Teknik, Program Studi Teknik Informatika \\ Universitas Muria Kudus \\ Email: muhammad.nurkamid@umk.ac.id \\ Tri Listyorini \\ Fakultas Teknik, Program Studi Teknik Informatika \\ Universitas Muria Kudus \\ Email: trilistyorini@umk.ac.id
}

\begin{abstract}
ABSTRAK
Dalam pembuatan paper ini sebagai syarat menunjang skripsi akan dibuat gagasan berupa sebuah prototype alat yang akan digunakan untuk membantu masyarakat untuk mengatasi masalah kejahatan yang terjadi ketika disuatu lokasi yang menandakan indikasi pembegalan, kecelakaan, serta semua indikasi yang dapat membahayakan masyarakat. Untuk penindak lanjutan masalah tersebut akan dibuatlah suatu prototype yang dibangun menggunakan microkontroler Arduino dan modul penunjang berupa sim 8001, modul gps neo 6m serta Arduino yang akan digunakan sebagai media dan controller yang akan mekeksekusi program yang akan di buat. Smart key chain tracking alarm alert ini merupakan alat yang akan digunakan oleh masyarakat yang dapat membantu ketika kita mengalamai insiden berupa penculikan, serta hal yang membutuhkan bantuan orang lain. Bentuk dari alat yang akan dibuat akan berbentuk gantungan kunci yang ringkas dan dapat disembunyikan dan cara kerja dari alat ini adalah dengan cara menekan poin button yang terintegrasi dengan system Arduino kemudian akan diproses dan Arduino akan mengirimkan sms berupa teks alert dan lokasi yang akan memberitau lokasi insiden yang akan di terima oleh nomor handphone yang sudah di inputkan dalam program.
\end{abstract}

Kata kunci: smart key chain, key chain alarm alert, key chain alarm

\begin{abstract}
In making this paper as a condition to support the thesis, an idea will be made in the form of a prototype tool that will be used to help the community to overcome the problem of crime that occurs when a location indicates indications of hijacking, accidents, and all indications that could endanger the community. To follow up on the problem, a prototype will be built using an Arduino microcontroller and a support module in the form of an $800 \mathrm{sim}$, a neo $6 \mathrm{~m}$ gps module and Arduino which will be used as a media and controller that will execute the program to be made. This smart key chain tracking alarm alert is a tool that will be used by the community that can help when we experience an incident in the form of kidnapping, as well as things that need help from others. The form of the device to be made will be in the form of a concise and concealed key chain and the workings of this tool are by pressing the button points integrated with the Arduino system and then it will be process and Arduino will send an SMS in the form of text alerts and locations that will
\end{abstract}


notify the location of the incident will be received by the cellphone number that has been inputted in the program

Keywords: smart key chain, key chain alarm alert, key chain alarm

\section{PENDAHULUAN}

Teknologi sekarang merupakan kebutuhan bagi masyarakat Indonesia, dalam era seperti ini kecanggihan teknologi adalah dukungan dalam kehidupan masyarakat yang dapat memudahkan untuk melakukan mobilitas dan mempercepat waktu dalam suatu pemecahan masalah, salah satunya teknologi yang sangat banyak digunakan di era sekarang ini yaitu handphone yang digunkan untuk melakukan komunikasi serta memperoleh informasi dari dunia digital dimana dapat memberikan wawasan pada pengguna serta mempermudah segala urusan mobilitas dengan sangat mudah karna tidak memerlukan pertemuan secara langsung dan dapat di wakilkan melalui virtual video.

Kemajuan dalam bidang teknologi yang ada dalam setiap kehidupan manusia sekarang sangat berada tepat dalam manusia dan selalu dipakai bahkan di bawa kemanapun dengan segenggam teknologi di tangan dan dengan kemudahan yang di berikan berupa handphone manusia tentu sangat di mudahkan karna hanya memegang device yang berukuran tak lebih dari 7inch saja manusia bisa mengakases seluruh dunia untuk mendapat informasi dan dapat saling melakukan hubungan dengan manusia lain.

Teknologi mempunyai dampak positif dan negatif salah satunya merupakan kurangnya empati kepada manusia lain yang mengakibatkan sulit berdiskusinya antar manusia dan kurangnya perasaan untuk saling menyapa dengan yang lain karna terbiasa berhadapan dengan mesin. Namun teknologi juga mempunyai dampak positif salah satunya merupakan pengaksesan informasi menggunakan google dimana informasi yang sangat luas dapat diakses gratis dan bebas tanpa di tutup - tutupi yang mengakibatkan manusia memiliki kecerdasan untuk literasi dan juga ada teknologi GPS yang digunakan untuk melakukan maping maupun melakukan pencarian lokasi yang sekarang banyak digunakan oleh aplikasi untuk memberikan titik koordinat yang mempermudah dalam menemukan lokasi , sekarang banyak digunakan untuk kepentingan jual beli fitur ini sangat disukai masyarakat karna mempermudah memberikan alamat dengan sekali tekan secara device to device.

Pengembangan dari sitem GPS juga sekarang di pakai dalam pembuatan sistem keamanan yang banyak dilakukan untuk melakukan penyelidikan kepolisian untuk melakukan aktivitas pencarian data yang tidak diketahui oleh manusia yang akan diselidiki.

Dalam kehidupan GPS sangat penting digunakan selain mempermudah juga GPS memberikan sistem keamanan yang dapat digunakan antar manusia untuk mencari bantuan menggunakan sistem GPS yang dapat digunakan yaitu pada fitur share lokasi yang di kembangkan untuk memberikan otomatisasi sistem bahaya.

Pembuatan teknologi dalam bidang keamanan sangat banyak di gunakan dan di kembangkan akan tetapi modus kejahatan yang berubah - ubah memerlukan banyak inovasi dan kecanggihan teknologi yang harus di perbaharui untuk meningkatkan efisiensi dan efektifitas teknologi yang akan digunakan.

Indonesia merupakan negara berkembang yang mempunyai masyarakat yang banyak yang mana mempunyai ekonomi yang beragam dan mempunyai kesenjangan yang sangat berbeda antar individu dari kesenjangan ini banyak kecemburuan kesenjangan yang kemudian mengakibatkan kejahatan yang muncul ketika batas kemampuan masyarakat yang sudah tidak dapat melakukan proses untuk mencari nafkah untuk keluarganya maka dari itu banyak juga masyarakat yang melakukan kejahatan social yang bertujuan untuk mmenuhi kebutuhan ekonomi.

Dalam kasus ini pada era teknologi banyak masyarakat yang cenderung bergantung pada teknologi dan lupa akan kesehatan dan keselamatan dirinya munculah fenomena - fenomena baru seperti penyakit mata dan ketergantungan terhadap gadget dan melupakan keselamatan karna pemakaian yang tidak wajar, ini merupakan keteledoran dan kesempatan terjadinya tidak kejahatan seperti pembegalan, penculikan anak, kecelakaan yang mana semua kasus itu dapat merugikan pribadi masyarakat karna kurang perdulinya ke dunia nyata karna terpengaruh ke dunia maya. 
Dikutip dari (Badan Pusat Statistik) menyatan angka kejahatan tahun 2016-2017 data mengalami penurunan 1,22\% memperlihatkan pola fluktuatif namun 2016-2017 mengalami penurunan menjadi 1,08\% namun pada saat tahun 2017-2018 mengalami kenaikan kembali sebanyak $1,11 \%$ dimana kejahatan meningkat dari titik terendah karna kesenjangan yang semakin terlihat dan kebutuhan yang semakin meningkat dimana kejahatan baru muncul yaitu kasus kejahatan begal dan penculikan anak mendominasi dalam presentase yang cenderung tinggi dan banyak kasus yang terungkap.

Dalam pengerucutan data yang di ambil dari daerah yang akan dijadikan acuan khususnya di kota Kudus Jawa Tengah penelitian dilakukan dengan melakukan identifikasi maslah kasuh kehilangan anak yang berlangsung beberapa tahun lalu tepatnya 2017 fenomena penculikan muncul dan mengakibatkan banyak masyarakat resah dan kuatir terhadap keselamatan anaknya karna ada suatu laporan mengenai isu penculikan namun setelah ditelusuri lebih lanjut kepada Polres Kudus berita tersebut merupakan isu yang tidak terbukti namun masyarakat di wilayah kota kudus masih khawatir mengenai berita tersebut karna fokus masalah ada pada anak anak mereka yang masih masih anak anak dan susah dicari maupun di lacak karna usia mereka.

Dari kasus penculikan anak pihak KPAI kudus memberikan wawasan apa saja yang memicu kejahatan penculikan, penculikan terjadi karna anak di pakaikan benda yang berhaga seperti anting, kalun, cincin yang mencolok, yang marak terjadi anak di gunakan sebagai suplay organ yaitu penjualan organ dalam sebagai donor selanjutnya anak di jadikan untuk eksekusi kejahatan seksual yang banyak terjadi di lingkungan tertutup mengenai wawasan yang di berikan pihak KPAI Kudus mengenai beberapa hal yang memicu proses penculikan, penelitian ini di diskusikan dan di terangkan untuk pengambilan keputusan masalah yaitu pada bagaimana cara mengatasi perihal penculikan yang sangat menghawatirkan pihak orang tua.

Dari semua fenomena dan semua masalah yang diungkapkan oleh pihak yang mengawasi mengenai anak - anak yang dapat memicu timbulnya kasus penculikan maka di buatlah suatu alat yang terbuat dari mikrokontroler yang akan terintegrasi dengan smartphone orangtua anak yang dapat melakukan pengiriman dan pesan bahaya yang otomatis akan masuk apabila tombol akan di picu. Pernyataan pihak KPAI kudus mengenai bagaimana cara mengatasi dan cara memberikan rasa aman pada orang tua merupakan fokus dari alat yang akan diciptakan.

\section{METODE PENELITIAN}

\subsection{Metode Pengembangan Sistem Prototype}

Prototype merupakan versi awal dari suatu sistem perangkat lunak maupun kumoulan sistem yang akan dibuat dalam bentuk terakhir yang memungkinkan sistem dapat diakses dan di pakai secara langsung oleh pengguna untuk kemudian dijalankan sebagai uji tes maupun taks yang akan digunakan untuk melakukan fungsi yang telah di rancan dan di persiapkan sebelumnya, yang digunakan dalam mendemonstrasikan konsep-konsep, percobaan rancangan, dan menemukan lebih banyak permasalahan dan solusi yang memungkinkan. (Sommerville, 2011)

Sistem prototype memperbolehkan pengguna untuk mengetahui bagaimana sistem berjalan dengan baik. Penggunaan metode prototyping didalam penelitian ini bertujuan agar peneliti mendapatkan gambaran aplikasi yang akan dibangun melalui tahap pembangunan aplikasi prototype terlebih dahulu yang akan dievaluasi oleh user. Aplikasi prototype yang telah dievaluasi oleh user selanjutnya akan dijadikan acuan untuk membuat aplikasi yang dijadikan produk akhir sebagai output dari penelitian ini secara konsep dalam prototype ini mengandung dua unsur penunjang yaitu bagian hardware dan software yang akan saling di integrasikan antar perangkat karna memerlukan dual konsep secara sistem dan secara pemakaian. (Prasetyo and Ambarsari, 2015)

Prototyping dimulai dengan mendengarkan kebutuhan user (pelanggan) dan mendengarkan masukan dari pengguna tersebut. Kemudian, pengembang dan pengguna bertemu dan bersama-sama menentukan tujuan keseluruhan untuk perangkat lunak yang akan dibangun dan mengidentifikasi persyaratan dan kebutuhan yang diperlukan. Selanjutnya, pengembang membuat sebuah gambaran tentang implementasi dan pengaplikasian resource yang akan digunakan untuk membangun sistem, 
yang akan dibangun dan selanjutnya dapat dilakukan presentasi atau pemaparan kepada penguji. Gambaran tersebut berfokus pada representasi aspek-aspek implementasi algoritma dengan device yang akan digunakan dalam pembangunan yang akan terlihat oleh pengguna dan penguji.

Metode prototyping memiiki beberapa keunggulan diantaranya ialah:

- Pengembang sistem dan pengguna saling berkomunikasi khususnya dalam hal penyamaan persepsi terhadap pemodelan sistem yang akan menjadi dasar pengembangan sistem operasionalnya.

- Pelanggan/pengguna ikut terlibat secara aktif dan berpartisipasi dalam menentukan model sistem dan sistem operasionalnya sehingga pengguna akan puas karena sistem yang dibuat sesuai dengan keinginan dan harapannya, dalam sistem dan desain prototype merupakan unsur percobaan dan hasil akhir akan mengacu pada unsur percobaan.

- Sistem yang dibangun memiliki kualitas yang diinginkan karena sesuai dengan kebutuhan yang ada.

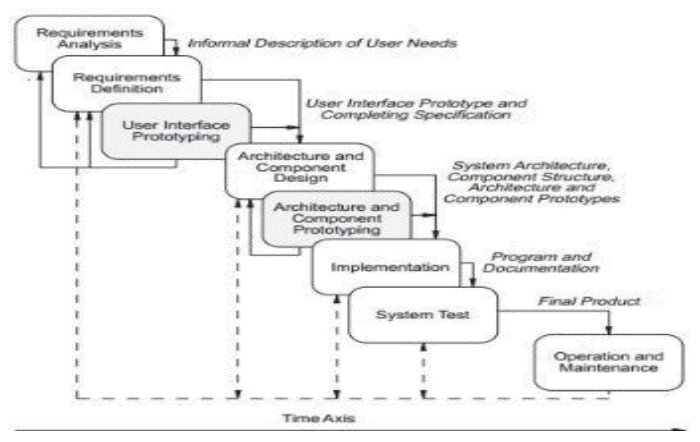

Gambar 1. Prototyping Model [4]

Gambar 1 diatas menjelaskan mengenai alur pengembangan sistem dengan menerapkan metode Prototyping-Oriented Software. Tahap pertama yang harus dilakukan adalah menganalisis kebutuhan dan mendefinisikan kebutuhan mengumpulkan data, algoritma, dan parameter yang akan dipakai dalam memberikan batasan proses dan melakukan perhitungan yang pasti agar sistem berjalan sesuai dengan kondisi perhitungan algoritma dan tidak mengalami error dalam proses compailer parameter yang ditangkap oleh sistem tersebut. Kebutuhan tersebut adalah kebutuhan pengguna serta kebutuhan yang akan membantu pengguna untuk melakukan proses identifikasi agar proses otomatisasi dapat berjalan lancar dan terbantu karna sistem dapat melakukan analisa secara langsung dan akurat karna berdasar algoritma. Selanjutnya pada tahap kedua yakni melakukan pembuatan prototype dari aplikasi software yang akan dibangun, dimulai dengan user interface prototyping dan kemudian dilanjutkan hingga penyusunan arsitektur dan komponen-komponen yang berkaitan dengan aplikasi software maupun hardware yang akan dibangun tersebut. Selanjutnya dilakukan pengembangan sistem, dimana aplikasi akan dibangun sesuai dengan prototype yang telah dibuat sebelumnya, dan setelah aplikasi berhasil dibuat sesuai dengan kebutuhan maka dilakukan proses pengujian aplikasi sebelum aplikasi tersebut diimplementasikan, pengujian tersebut bisa dilakukan dengan pengujian black box maupun pengujian white box testing yang mengacu pada hasil akhir dari implementasi software ke hardware dan kemudian akan dilakukan integrase antar device untuk melakukan pengecekan apakah alur algoritma dan alur planing yang dibutuhkan dan di setting sebelumnya sesuai atau masih belum sesuai karna ada kesalahan teknis dari pengembang.

\subsection{Unified Modeling Language (UML)}

Unified Modeling Language (UML) bukanlah suatu proses melainkan bahasa pemodelan secara grafis untuk menspesifikasikan, memvisualisasikan, membangun, dan melakukan dokumentasi secara terstruktur seluruh artifak atau urutan yang dapat dilakukan secara texsture dengan menguji alur dan kondisi sesuai dengan sistem perangkat lunak. Penggunaan model ini bertujuan untuk mengidentifikasikan bagian-bagian yang termasuk dalam lingkup pengembangan 
sistem yang dibahas dan bagaimana hubungan antara sistem dengan subsistem maupun sistem lain di luarnya.

Unified Modeling Language (UML) adalah sebuah bahasa yang berdasarkan grafik/gambar untuk memvisualisasi, menspesifikasikan dari sebuah sistem pengembangan software berbasis object oriented.

Dari pengertian diatas penulis menyimpulkan bahwa Unified Modeling Language (UML) merupakan bahasa pemodelan yang berbentuk grafis yang digunakan untuk menspesifikasikan suatu sistem perangkat lunak untuk pengelompokan sebagai kondisi input, proses, output yang dapat digunakan untuk melakukan identifikasi trial error agar lebih mudah dan tidak mempersulit konfigurasi pada saat sistem maupun subsistem mengalami kondisi error.

\subsection{Rancangan Sistem}

Perancangan sistem merupakan kumpulan dari blok kerja yang akan dibuat yaitu mengenai smart key chain alarm alert yang akan dibangun alur dari perancangan system ini dimulai dai sensor yang terintegrasi dengan microcontroller yang akan mengambil parameter yang kemudian di proses microcontroller Arduino nano yang akanmelakukan komputasi data dan akan mengeluarkan fungsi PWM yang akan mengatur input outpun dan menyalakan modul gsm yang kemudian akan melakuakn komunikasi dengan smartphone, kemudian akan menyalakan modul gps yang akan mengambil data yang akan dikirimkan menggunakan sim 8001 dan kemudian akan di gunakan sebagai sms getway untuk dibuka dengan google maps dan akan menunjukan lokasi.

\subsubsection{Perangkat lunak}

Perangkat lunak merupakan bagian penunjang yang sangat penting dan sangat berguna dalam perancangan yang mana seluruh aliran data dan data yang akan dipakai dan digunakan terdapat dalam perangkat lunak untuk mengatur seluruh proses yang akan dipakai sebagai output nantinya.

Program perangkat lunak yang akan dipakai untuk memasukan data parameter yang akan digunakan menggunakan aplikasi perangkat luna Arduino IDE yang dapat di ambil secara open source dan dapat di gunakan sebagai pengembang secara gratis. 


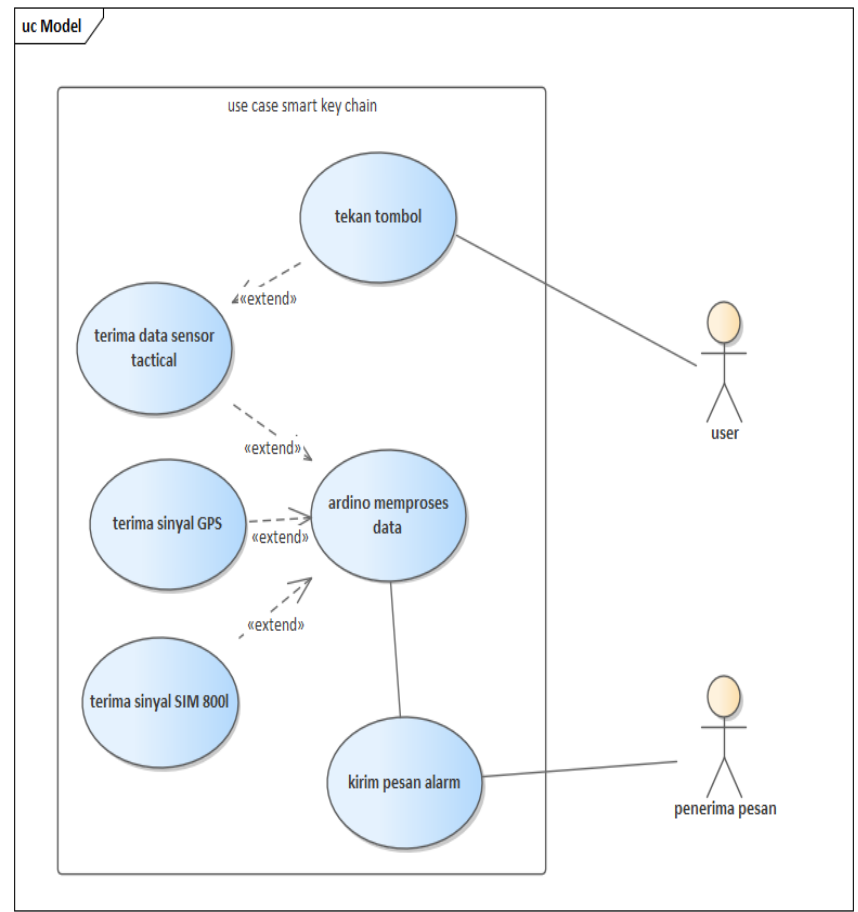

Gambar 2. Use Case Diagram

Gambar 2 merupakan gambar usecase alat yang di buat yang akan menggunakn dua actor sebagai user, user pertama merupakan sebagai korban dan user kedua merupakan sebagai orang tua dari korban maupun nomor yang dianggap penting untuk di hubungi ketika terjadi insiden.

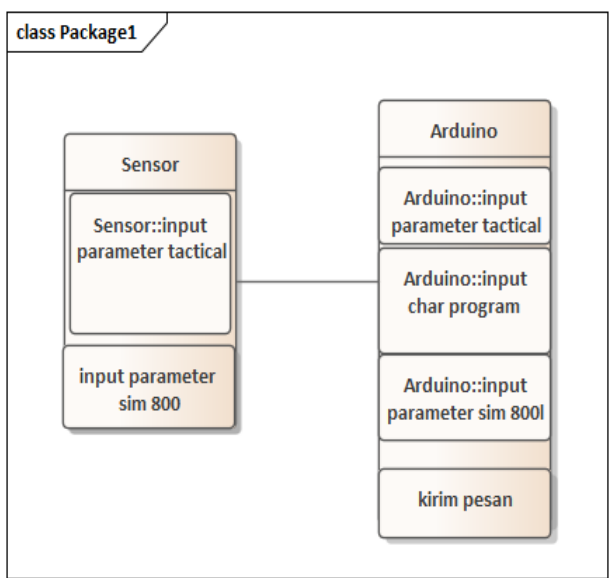

\section{Gambar 3. Class Diagram}

Class diagram system menjelaskan mengenai interaksi sistem kerja dari pengaplikasian parameter data yang berjalan melalui interaksi mesin yang dapat dilakukan pemrosesan berdasarkan hardware yang akan di gunakan dan menggunakan inisialisasiyang akan di gunakan untuk kebutuhanan sistem. 


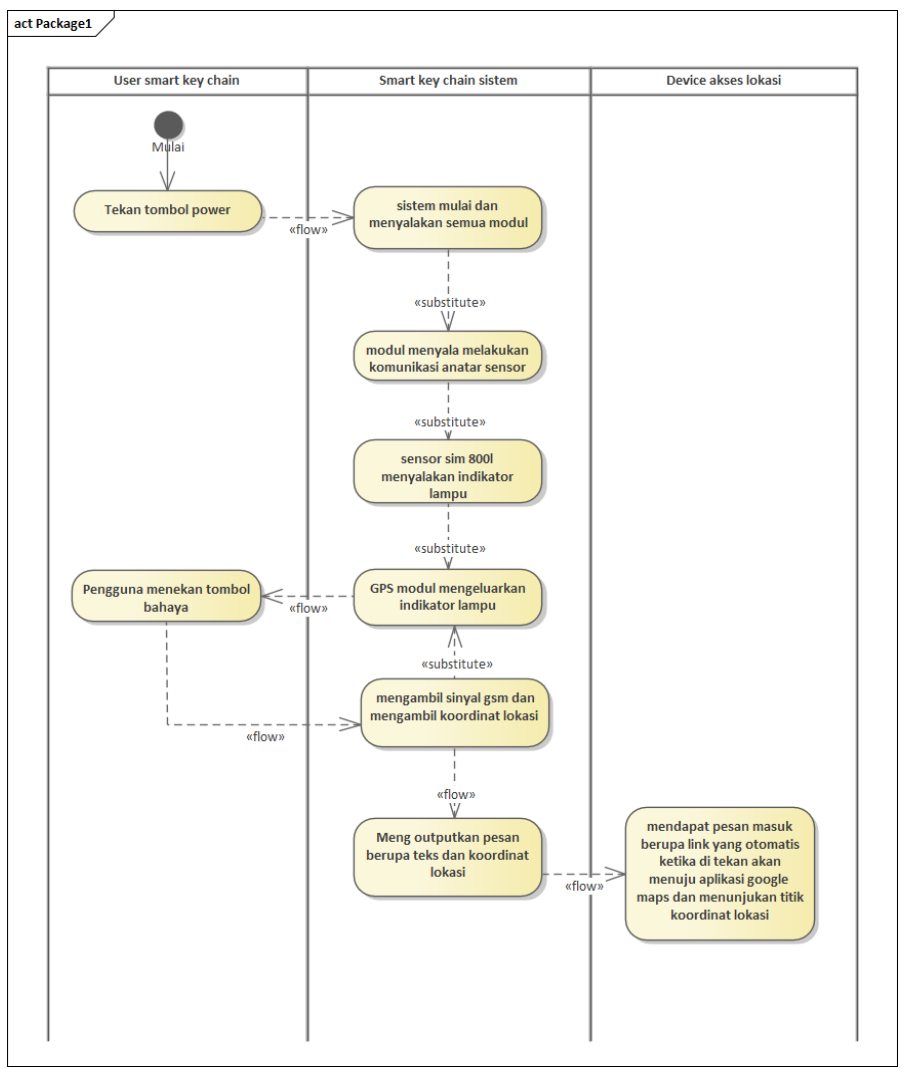

Gambar 4. Activity Diagram

Activity diagram diatas merupakan penggambaran sistem sesuai alur penggunanaan yang akan digunakan ketika menyalakan alat dan menggunakanya untuk meminta bantuan dan menyalakan fungsi utama serta urutan yang akan dilakukan untuk mengetahui kondisi alat mengenai kesiapan alat saat akan diunakan.

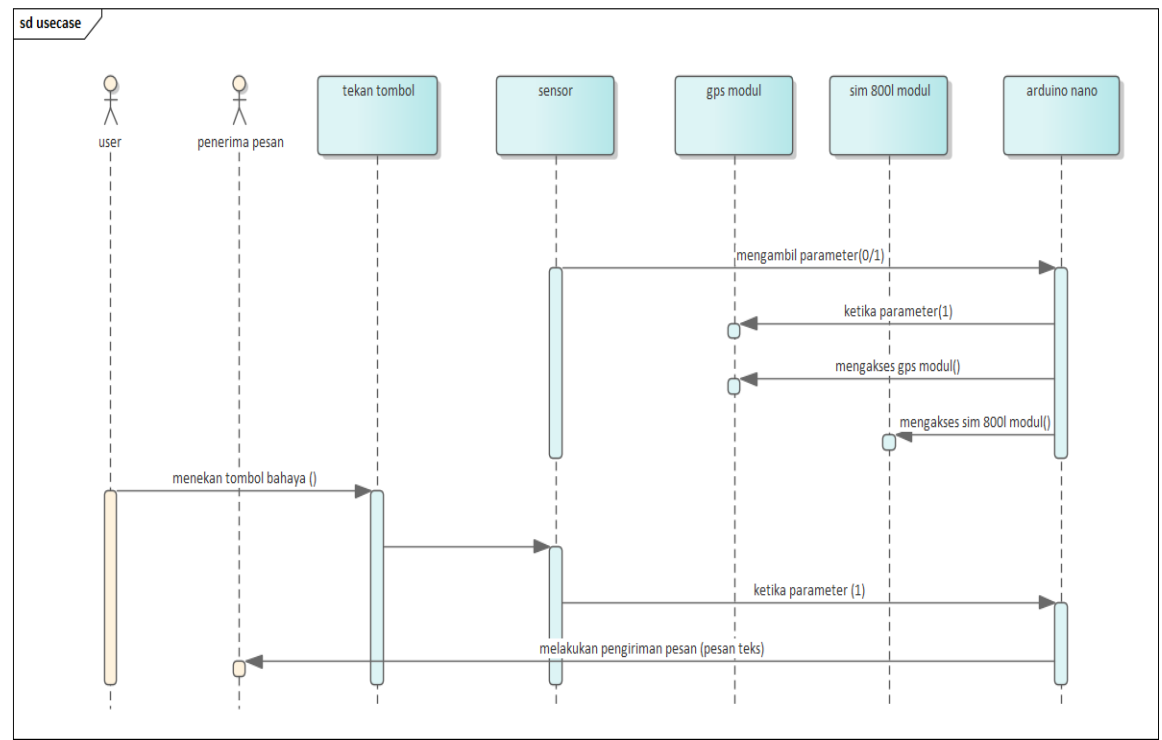

Gambar 5. Sequence Diagram 
Gambar 5 merupakan gambaran alur sistem yang dibuat berdasarkan akses masing masing modul yang akan bekerja sesauai urutan kerja sistem yang akan digunakan untuk proses interaksi dengan user maupun pengguna.

\subsubsection{Perangkat keras}

Perangkat keras merupakan penggabungan semua komponen untuk membentuk program yang sudah di atur dalam sintaks perangkat lunak dan sesuai dengan pin Arduino yang akan digunakan dan akan di pakai untuk melakukan kerja dari masing - masing modul yang dapat mengeluarkan akses data yang dibutuhkan dan memberikan parameter agar perangkat lunak bisa mengolah dari system yang terbangun menggunakan komponen yang telah tersusun dan sesuai.

Berikut merupakan gambar diagram rancangan:

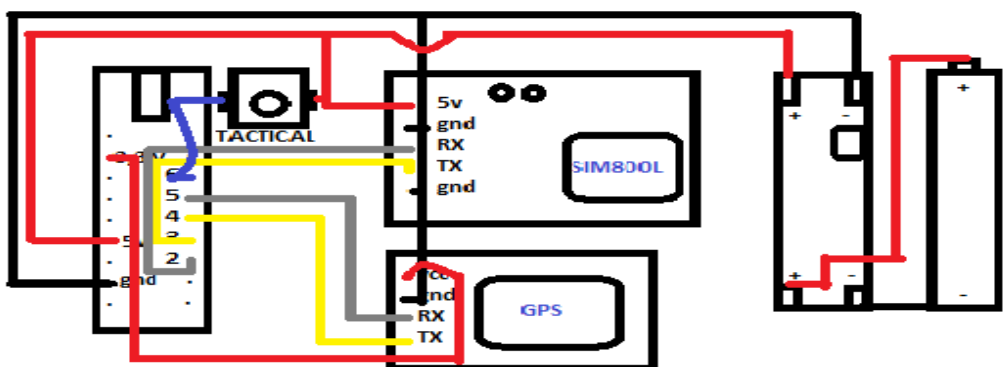

\begin{tabular}{|ll|}
\hline MERAH & POSITIF ATAU VCC \\
HITAM & NEGATIF ATAU gnd \\
ABU-ABU & RX \\
KUNING & TX \\
BIRU & Triger \\
\hline
\end{tabular}

\section{Gambar 6. Rangkaian Sistem Smart Key Chain Alarm Alert}

Dalam perancangan perangkat keras memerlukan tahap yang dipakai untuk merancang rangkaian elektronik sebagai jalur pemberian tegangan arus untuk

Berikut merupakan tahapan perancangan:

Tahap 1 Integrasi GPS

\begin{tabular}{ccc} 
No & Pin & Integrasi \\
\hline 1 & 4 & TX modul GPS \\
2 & 5 & RX modul GPS \\
3 & $3,3 \mathrm{v}$ & $5 \mathrm{~V}$ modul GPS \\
4 & Gnd & Gnd modul GPS
\end{tabular}

Tahap 2 Integrasi SIM 8001

\begin{tabular}{ccc} 
No & Pin & Integrasi \\
\hline 1 & 3 & TX modul GPS \\
2 & 2 & RX modul GPS \\
3 & $5 \mathrm{v}$ & 5V modul GPS \\
4 & gnd & Gnd modul GPS
\end{tabular}

Tahap 3 Integrasi Tactical Switch 
Jurnal SIMETRIS, Vol 11 No 2 November 2020

P-ISSN: 2252-4983, E-ISSN: 2549-3108

\begin{tabular}{lcc}
\hline No & Pin & Integrasi \\
\hline 1 & $5 \mathrm{v}$ & Triger \\
2 & 6 & Triger \\
\hline
\end{tabular}

Tahap 4 Integrasi Battery Dengan Step Up Down

\begin{tabular}{lcc}
\hline No & Pin & Integrasi \\
\hline 1 & + & Positife 3,7 \\
2 & - & Negative 0 \\
\hline
\end{tabular}

\section{HASIL DAN PEMBAHASAN}

Berikut merupakan hasil ketika alat dihidupkan

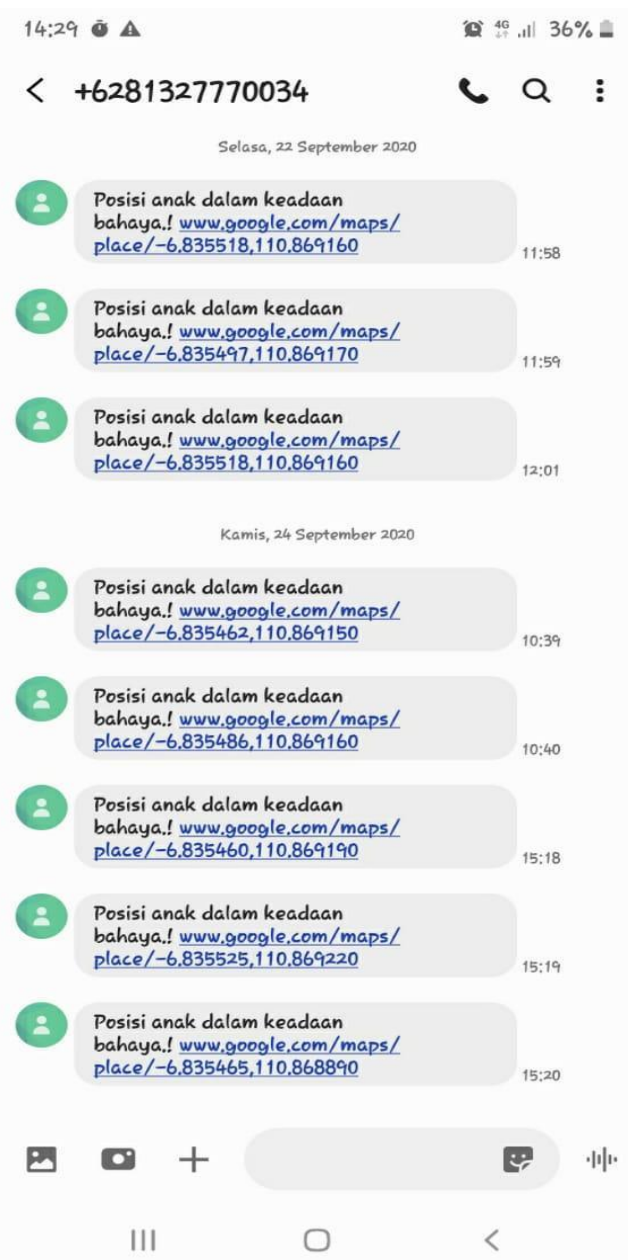

Gambar 7. Pesan Pemberitahuan 
Ini adalah pesan yang dikirimkan oleh alat yang merupakan hasil alat yang dilakukan trigger untuk berkomunikasi antar pengguna.

\section{KESIMPULAN}

Dari segi pengujian yang dilakukan dan prototype yang sudah jadi alat ini mampu mengirimkan pesan dan mampu mendapat koordinat lokasi yang cenderung singkat karna mampu mendapat sinyal GSM lebih cepat karna sim yang digunakan menggunakan antine external serta GPS modul yang diguanakan mampu mengambil koordinat lokasi lebih akurat karna mengambil data yang cukup singkat sesuai dengan sinyal gps dari satellite, alat ini memiliki fungsi yang sangat penting untuk pelacakan dan melakukan permintaan bantuan bahaya yang akan digunakan untuk melakukan evakuasi pada korban.

Penggunaan alat ini juga mudah karna hanya menggunakan dua tombol yang ringkas dan mudah digunakan oleh anak dibawah 10 tahun maupun diatasnya.

\section{DAFTAR PUSTAKA}

[1] Anike, M. and Anike, M. (2019) 'APPLICATION EMERGENCY PANIC BUTTON (AEPB) BERBASIS ANDROID (Studi Kasus RS St. Carolus Boromeus-Bello)', Sistemasi, 8(3), p. 367. doi: 10.32520/stmsi.v8i3.499.

[2] Hadi, F. L. (2018) 'Rancang Bangun Sistem Keamanan Kendaraan Roda Dua dengan Menggunakan SMS Berbasis Arduino Mega 2560', Hadi, F. L. (2018). Rancang Bangun Sistem Keamanan Kendaraan Roda Dua dengan Menggunakan SMS Berbasis Arduino Mega 2560.

[3] Kharisma, O. B. et al. (2019) 'Development of location tracking system via short message service (SMS) based on GPS unblox neo-6m and sim 8001 module Development of location tracking system via short message service (SMS) based on GPS unblox neo-6m and sim 8001 module'. doi: 10.1088/1742-6596/1363/1/012002.

[4] Prasetyo, Y. A. and Ambarsari, N. (2015) 'PENGEMBANGAN WEB E-COMMERCE BOJANA SARI MENGGUNAKAN METODE PROTOTYPE’, 2(1), pp. 1042-1056.

[5] Publikasi, N. et al. (2018) 'ARDUINO DAN ANDROID (Studi Kasus Pasar Talang Banjar Kota Jambi Timur) ARDUINO DAN ANDROID (Studi Kasus Pasar Talang Banjar Kota Jambi Timur)'.

[6] Rizkidiniah, F., Yamin, M. and Muchlis, N. F. (2016) 'Perancangan Dan ImplementasiPrototype Sistem GPS (Global Positioning System) Dan SMS Gateway Pencarian Kendaraan Bermotor Berbasis Arduino Uno', semanTIK, 2(2), pp. 87-92.

[7] Sommerville, I. (2011) Software Engineering. Nineth. Massachusetts: Addison-Wesley.

Subhiyakto, E. R. and Astuti, Y. P. (2020) 'Aplikasi Pembelajaran Class Diagram Berbasis Web Untuk Pendidikan Rekayasa Perangkat Lunak', Simetris: Jurnal Teknik Mesin, Elektro dan Ilmu Komputer, 11(1), pp. 143-150. doi: 10.24176/simet.v11i1.3787. 